\title{
Augmenting Angri: Murals in AR for Urban Regeneration and Historical Memory
}

Alessandra Pagliano

\section{Abstract}

Augmenting Angri is a project aiming at preserving the memory of about twenty murals located in the historical centre of the small city of Angri (SA) using ICT and in particular Augmented reality. The project has been carried on in 2020 with the students attending the integrated course of Visual Expression (professors A. Pagliano and P. Vitolo) in the Master's Degree Course in Design for the Built Environment.

Augmenting Angri consists of an innovative valorisation path in Augmented reality which expand the narrative message of the old murales thanks to the digital contents (audio, video, animations and 3D models), sometime replacing them back, in case of totally disappeared murales.

\section{Keywords}

street art, augmented reality, cultural heritage, artivive, murales.

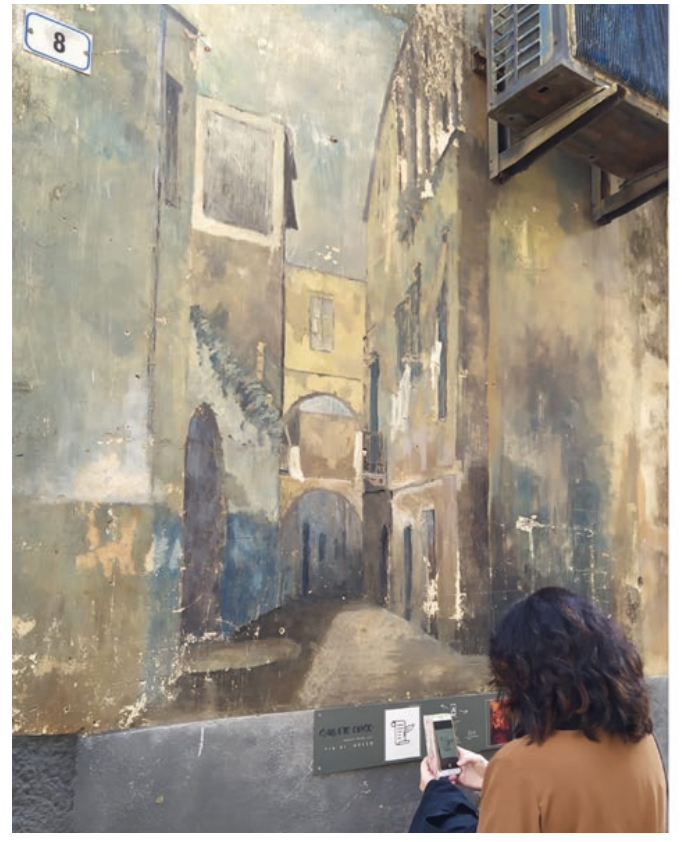

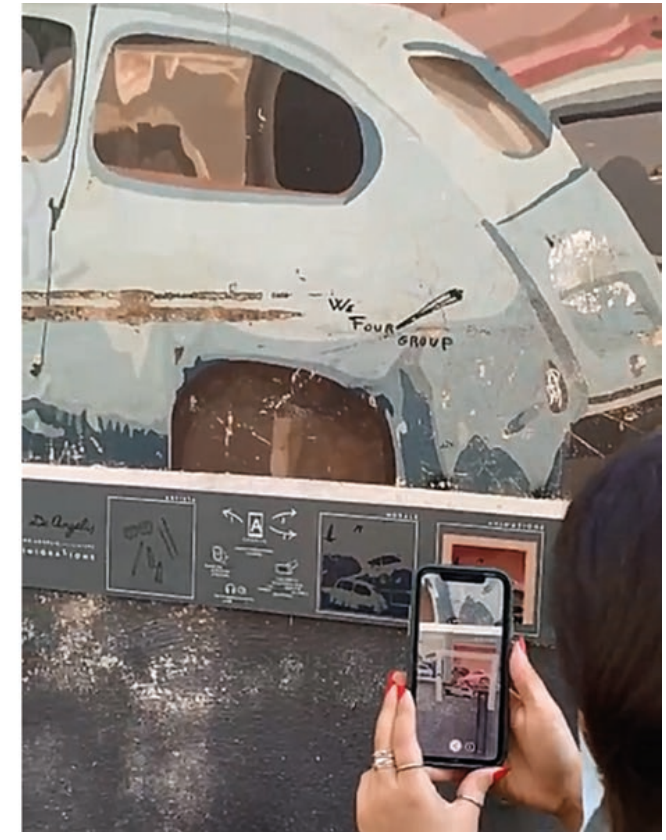

doi.org// 0.3280/oa-686.39 


\section{From Graffiti to Street Art in Contemporary Cities}

Street art emerged as an artistic practice since the 1960s in the United States, in form of graffiti, namely the tags of the writers who usually are young people from degraded suburbs who leave a testimony of their problems on empty walls, thereby performing an unauthorised and illegal action. Today, street art has evolved considerably, abandoning graffiti in favour of painted images, often characterised by a high artistic quality, which has attracted the interest of critics and art historians, becoming today one of the most established forms of urban art.

Abandoned or degraded spaces are enhanced with fast, low-cost and high-impact interventions that sometimes become the spark and the starting point for a following physical redevelopment and social regeneration. In the abandoned places, in the residual spaces [Bauman 2002], in those buildings without any quality and in the so called 'non-places' [Augé 1996], urban art is a powerful tool capable of reopening the dialogue with the urban context through imagination, transforming these inexact spaces into active elements of the urban and social landscape. The modification of an abandoned space through urban art intervenes on the cultural and perceptive aspects capable of influencing both the physical space and the inhabitants' habits, superimposing new signs on the pre-existing ones and thus creating a 'new space' through the interaction of the physical volumes and the illusory appearance superimposed on them. So, the murals adopt those walls, transforming and offering them a new role in the surrounding space. The shape, size and subject of a mural are thus a spatial response to a latent urban question.

When murals are socially accepted for their aesthetic contribution to the urban environment, the city appropriates the works. In such circumstances, citizens strongly assert their need to own and preserve these artworks, requiring them to remain. The request for conservation and permanence emerges a posteriori, thanks to a slow process of social recognition of their value.

But the problem related to the maintenance of murals is an ongoing issue, which goes from the recognition of the mural as an artwork to the need for its protection in order to preserve and pass on its value to future generations. The painter holds the paternity but not the ownership of the artwork, since it was painted it on other people's walls. Therefore, street artists are used to accept the temporary nature of the artwork itself, probably destined to be removed by the will of the real owner of the wall. Even in case of famous artists, transferring murals to museums is inappropriate because the very meaning of the mural would be altered if removed from the urban context which generated it, but also because it could be done against the will of the author, who instead generally accepts his/ her artwork to be perishable.

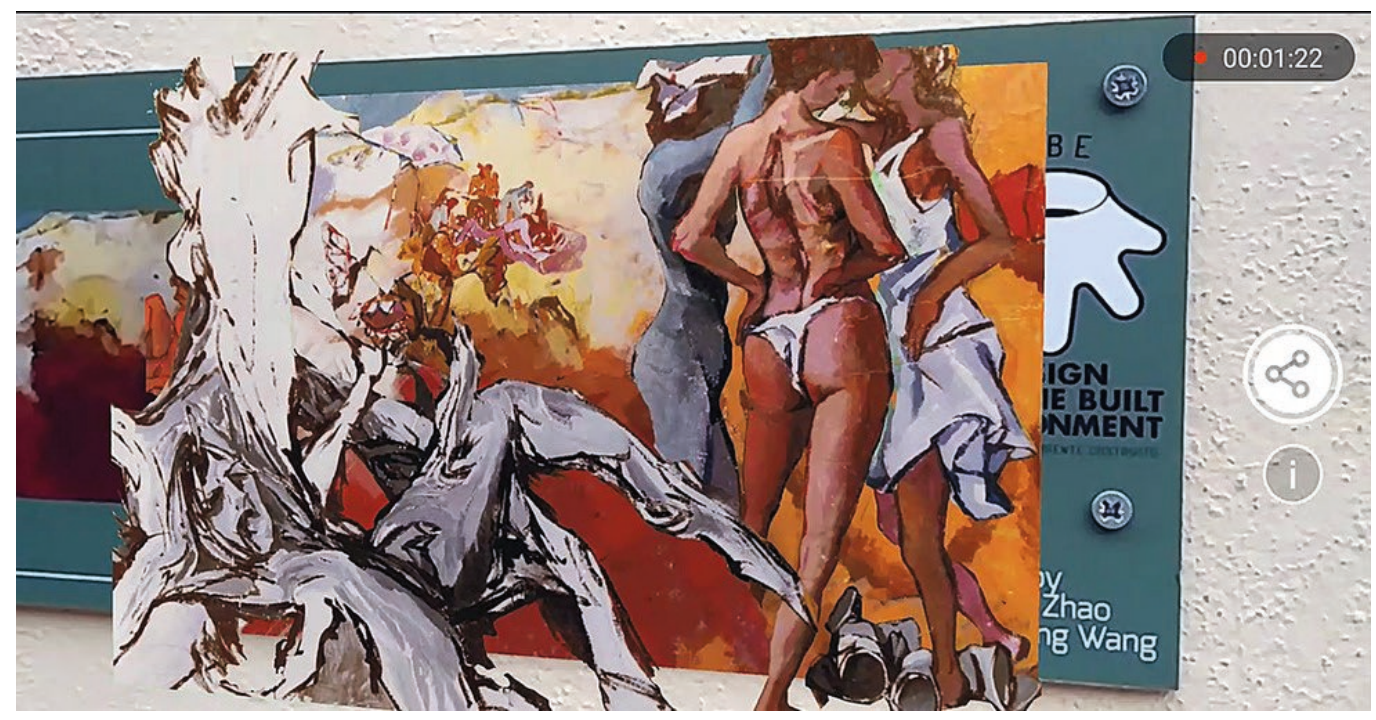


Street art is always exposed to the ever-changing conditions of the street and It's quite impossible to protect murals from the rain, snow, direct sunlight, or intense cold; protecting a street artwork, as in the very debated case of Banksy's mural in Via dei Tribunali ( $\mathrm{Na}$ ), recently covered with a glass that protects the painted image from the weather, profoundly alters the inner nature of a street mural.

This suggests that street art cannot be assumed as "finished" artwork, strictly linked only to the author, because the constant exposure to change is its inner nature and, perhaps, the only real way for it to remain authentic.

\section{Augmenting Angri: Augmented Reality to Valorize the Murals}

In terms of street art's protection and heritagization, the lack of defined and consolidated guidelines, due to both the high variability of the materials used by artists and the issues related to the ownership of works, produces an immobility that is far more damaging than the weathering itself.

Augmenting Angri is a project aiming at preserving the memory of about twenty murals located in the historical centre of the small city of Angri. The project has been carried on with the collaboration of the students attending the integrated course of Visual Expression (professors A. Pagliano and P. Vitolo) of the Master's Degree Course in Design for the Built Environment. The area of the old Angevin village is formed by two orthogonal streets that shap four insulae. The road axes are named according to their orientation with respect to the cardinal points (Via di Mezzo Sud, Via di Mezzo Nord ...) and extend close to the medieval castle. The murals in the Vie di mezzo were painted between 1982 and 1983 and constitute a pioneering urban art project, to bring collective attention back to the cultural value of Angri's historic centre, which was suffering from serious deterioration and subsequent abandonment after the 1980 earthquake.

The initiative was promoted by the municipal administration. Twenty artists, led by Gianni Rossi, transformed the four streets into an open-air gallery, by painting murals of various sizes and different subjects, which were inserted on the facades according to a variety of ways, in order to suit the morphology of the walls, with windows and doors instead of treating the facade as a blank canvas. The artists acted as spokesmen for the collective and personal malaise of the post-earthquake years, or in other cases they represented the most characteristic elements of Angrian identity, such as the agricultural vocation, deep religious devotion or local historical episodes.

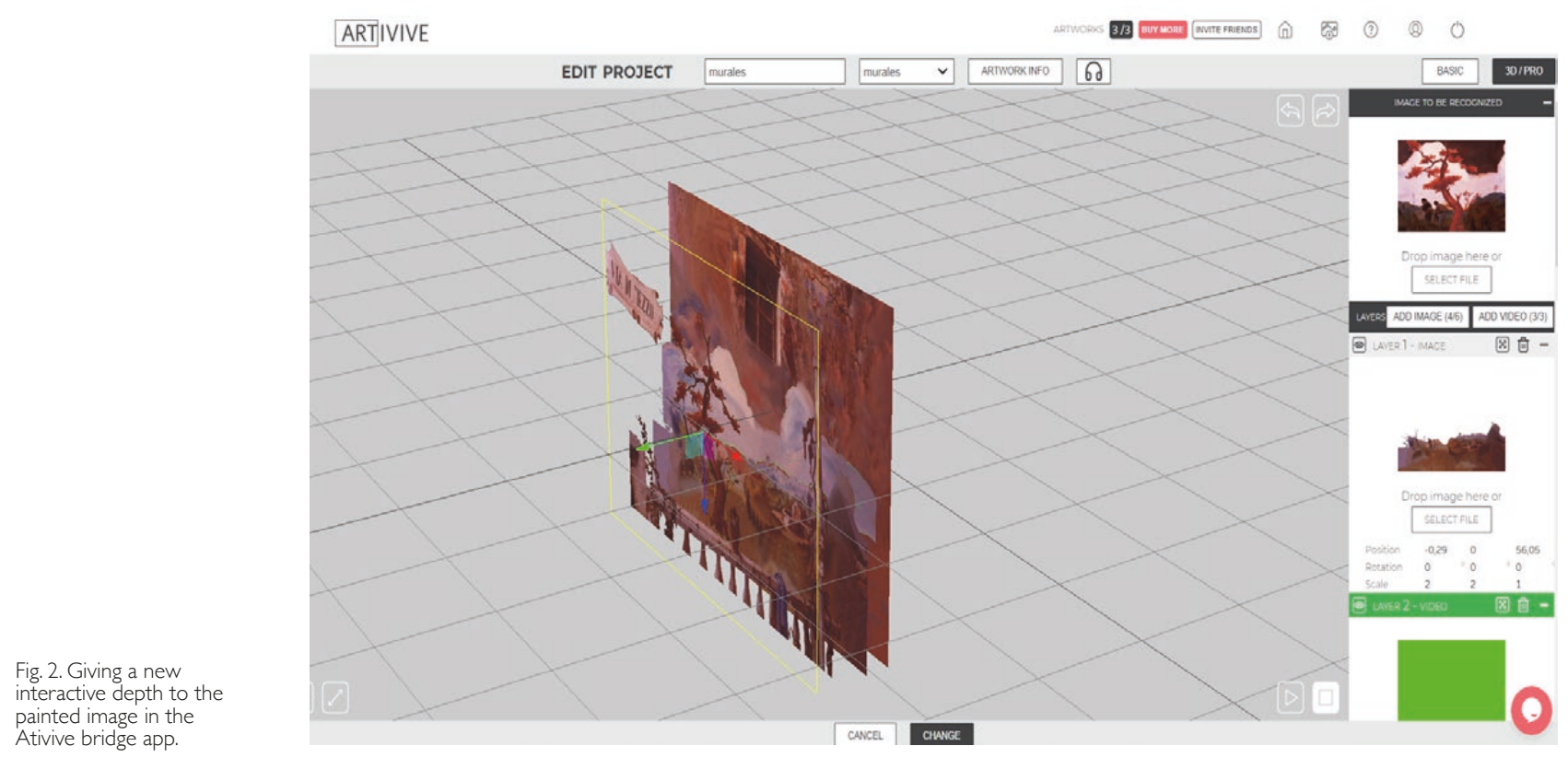


Severely degraded, very little remains today of the original murals, but a good photographic documentation and the potential of digital technology have enabled us to repropose each mural in the original locations, bringing them to life by means of short animations. In some cases, they totally disappeared, completely erased by the renovation of the building facades: in fact, some owners took over the buildings when the mural was at an advanced stage of deterioration and they were unable to perceive original artistic value and the role that the mural had for the collective memory. They simply identified them as signs of decay and removed them.

In our Augmenting Angri project, since it was not possible to carry out a pictorial restoration of the still remaining painted images, and since we also did not consider appropriate to remake (re-paint) those which completely disappeared a long time ago, the request of those places was immediately intended in a need to preserve the memory of that fruitful interaction between the beauty of the murals, their social message and the urban regeneration that they activated in that concentrated urban context. We designed an exhibition path supported by small printed panels, directly affixed to the façades and containing some markers activating augmented reality contents; in this way it was possible to bring the disappeared murals back to their original location. All the remaining murals, in most cases only partially visible, were reproduced in their original state, also enriching each artwork with additional narrative contents. Augmented reality digital contents, superimposed to the physical reality, create a surprising relationship among three different spatial dimensions: the perspective space represented in the mural, the digital space of the augmented content and the real one of the urban environment that is physically experienced by the public. Thus, each observer becomes an active subject of his/her own individual knowledge process according to a dynamic cognitive path. New digital technologies are in fact restructuring the relationship between experience and knowledge. In spite of the need to re-propose in those places the painted images that have now disappeared, the digitisation of the murals was not intended as a reproduction, a digital copy, even if faithful and accurate, but as the generation of a new mixed asset (both digital and Physical) that provides further knowledge. Ben Hicks defines this new digital asset as 'digital twin', remarking the differences with a simply digital prototype or model "as an appropriately synchronized body of useful information (structure, function, and behaviour) of a physical entity in virtual space, with flows of information that enable convergence between the physical and virtual states" [Hicks 2019]. According to the previous definition, digital twins in not a mere copy of the real object but a new object with data, functions, and features of the real one but added by the communication capabilities of the digital world. The reconfiguration of the cognitive process, typical of digital technologies and in particular of augmented reality, takes place only when the digital contents are experienced and lived, i.e. 'activated', by an observer. In fact, the designed semantic link is enabled and implemented only through individual interaction and experience with the designed knowledge contents. Today, the ability of cultural heritage to arouse emotions, establish links and stimulate curiosity can become effective if we take into account that contemporary users have completely changed: they are both 'digital immigrants' and 'digital natives' with different expectations, pre-existing knowledge, historical/cultural backgrounds and interpretative strategies. The students of the Design for the Built Environment course were encouraged to address their project to this new audience, uncovering the evocative power of each mural to develop and enhance its storytelling. The narrative aspect is, in fact, a good binder to combine emotions with information. Murals' painted scenes are the representation of a single moment, which remains eternally frozen and which the artist subtracted from a long-envisioned sequence of gestures and positions, by painting a crystallised motion. Each image has been analysed for its ability to suspend time with a hinted gesture, a gust of wind, a fleeting glance, a facial expression that become permanent. In this way the time is allowed again to flow before and after that suspended portrayed moment. The brief animations, designed to give life to the static painted scene, are slight variations of the portrayed configuration, as a simple temporal expansion of that moment. Augmented reality allowed us to integrate or change the state of each mural without compromising the physical state. The link between AR and murals' visual and pictorial aspects required a deep 
disciplinary study in terms of representation as a possible product of new ways of looking at reality, new perceptions and therefore new ways of interacting with perceived space.

Furthermore, the images of the Angrian village murals were also interpretated according to the category of the painted three-dimensional spatiality that regulates the reciprocal positions and distances between objects, background, architecture and the human characters acting there. The perspective space has been made interactively explorable again, beyond the point of view chosen by the artist, thanks to augmented reality, which allows the viewer to enter the space portrayed in the pictorial image thanks to the three dimensions restored to the mural in the virtual space. Each mural has been provided with a thin horizontal band, containing three printed images designed to be "markers" for digital content activation. By scanning one by one each marker with the open-source app Artivive, different digital content appear on observer's smart device: a short video clips narrating artist's life and poetry, an animated storytelling of the painted image and a three-dimensional model drawn according to parallel planes which, like a theatrical scenography, gives the perspective image a virtual three-dimensionality and an explorable spatial depth.

Augmenting Angri won funding from the Open Call Street Art 2020, funded by the Embassy and Consulate General of the Kingdom of the Netherlands. It was inaugurated in Angri on II October 2020 in the presence of the artists, university students, local authorities and the community.

\section{References}

Augè Marc (1996). Nonluoghi. Introduzione a una antropologia della surmodernità. Milano: Elèuthera.

Cristallini Elisabetta, Mania Patrizia, Petrilli Raffaella (eds.). (2017). Arte sui muri della città. Street art e urban art: questioni aperte. Roma: Round Robin Ed.

Hicks Ben (2019). Industry 4.0 and Digital Twins, Key Lessons FromNASA. Aug. 5. https://www.thefuturefactory.com/blog/24 ( I5th February 202 I)

Pagliano Alessandra (2019). Artistic experiments of urban acupuncture/Esperimenti artictici di agopuntura urbana. In TRIA Territori della ricerca su insediamenti e ambiente, 23 (2), pp. 17-28.

Rasheed Adil, San Omer, Kvamsdal Trond (2020). Digital Twin:Values, Challenges and Enablers From a Modeling Perspective. In IEEE Access, 8, pp. 21980- 22012.

Santabárbara Carlota (20।8). Street art conservation: beyond surfaces' restoration. In OPUS, Quaderno di storia architettura restauro disegno, 2. Roma: Gangemi editore International, pp. I47-162.

Simões Daniela V. (20I3). On graffiti and street art in Lisbon: towards Another Brick in the Wall. In Borriello Luca, Ruggiero, Christian (eds.), Inopinatum. The Unexpected Impertinence of Urban Creativity. Salerno: Arti Grafiche Boccia, pp. 63-78.

Simondon Gilbert (2014). Sulla tecno-estetica. Milano: Mimesis.

Zurlo Francesco, Arquilla Venanzio, Carella Gianluca, Tamburello Maria Cristina (20/8). Designing acculturated phygital experiences. In Zhang Linghao, Lam Yanyan, Xiao Dongjuan, Gong Miaosen, Shi Di (eds.). Cumulus Conference Proceedings. Wuxi:Wuxi Huguang Elegant Print Co.

Author

Alessandra Pagliano, Dept. of Architecture, University of Naples Federico II, alessandra.pagliano@unina.it 
